Article

\title{
Polydopamine-Assisted Silver Nanoparticle Self-Assembly on Sericin/Agar Film for Potential Wound Dressing Application
}

\author{
Liying Liu ${ }^{1}$, Rui Cai ${ }^{2}$, Yejing Wang ${ }^{1,2, *}$, Gang Tao ${ }^{1}$, Lisha Ai ${ }^{1}$, Peng Wang ${ }^{2}$, Meirong Yang ${ }^{1}$, \\ Hua Zuo ${ }^{3}\left(\mathbb{D}\right.$, Ping Zhao ${ }^{1,4}$ and Huawei He ${ }^{1,4, *}$ \\ 1 State Key Laboratory of Silkworm Genome Biology, Southwest University, Chongqing 400715, China; \\ 13341345@email.swu.edu.cn (L.L.); taogang@email.swu.edu.cn (G.T.); als123@email.swu.edu.cn (L.A.); \\ yangmeirong@email.swu.edu.cn (M.Y.); zhaop@swu.edu.cn (P.Z.) \\ 2 College of Biotechnology, Southwest University, Chongqing 400715, China; \\ cairui0330@email.swu.edu.cn (R.C.); modelsums@email.swu.edu.cn (P.W.) \\ 3 College of Pharmaceutical Sciences, Southwest University, Chongqing 400715, China; zuohua@swu.edu.cn \\ 4 Chongqing Key Laboratory of Sericultural Science, Chongqing Engineering and Technology Research Center \\ for Novel Silk Materials, Southwest University, Chongqing 400715, China \\ * Correspondence: yjwang@swu.edu.cn (Y.W.); hehuawei@swu.edu.cn (H.H.); \\ Tel.: +86-23-6825-1575 (Y.W. \& H.H.)
}

Received: 23 August 2018; Accepted: 19 September 2018; Published: 21 September 2018

\begin{abstract}
Silver nanoparticles (AgNPs) are extensively applied for their broad-spectrum and excellent antibacterial ability in recent years. Polydopamine (PDA) has great advantages for synthesizing large amounts of AgNPs, as it has multiple sites for silver ion binding and phenolic hydroxyl structure to reduce silver ions to AgNPs. Here, we mixed sericin and agar solution and dried at $65{ }^{\circ} \mathrm{C}$ to prepare a sericin (SS)/Agar composite film, and then coated polydopamine (PDA) on the surface of SS / Agar film by soaking SS/ Agar film into polydopamine solution, subsequently synthesizing high-density AgNPs with the assistance of PDA to yield antibacterial AgNPs-PDA-SS/Agar film. Scanning electron microscope (SEM), Fourier transform infrared spectroscopy (FT-IR) and X-ray diffraction (XRD) spectra indicated the successful synthesis of high-density AgNPs on the surface of PDA-SS/Agar film. PDA coating and AgNPs modification did not affect the structure of sericin and agar. Furthermore, water contact angle, water absorption and mechanical property analysis showed that AgNPs-PDA-SS/Agar film had excellent hydrophilicity and proper mechanical properties. Inhibition zone and growth curve assays suggested the prepared film had excellent and long-lasting antibacterial ability. In addition, it had excellent cytocompatibility on the fibroblast NIH/3T3 cells. The film shows great potential as a novel kind of wound dressing.
\end{abstract}

Keywords: polydopamine; silver nanoparticle; sericin; antimicrobial activity; cytocompatibility

\section{Introduction}

The antibacterial ability of a material surface is crucial to inhibiting the growth of bacteria on and around the material, which has great potential in food packaging and biomedical application [1]. Recently, nanomaterials have received increasing interest for their specific properties and applications in different fields. Silver nanoparticle (AgNP) is a brilliant nanomaterial, as it has a broad inhibitive effect against a variety of bacteria and fungus [2]. Surface immobilization of AgNPs is one of the most effective ways to increase the antibacterial property of materials [3].

Silk sericin (SS) is a natural hydrophilic macromolecular protein derived from silkworm cocoon. Sericin makes up $25-30 \%$ of silkworm cocoon, and it wraps silk fibroin fiber with a continuous, viscous 
layer that helps the formation of cocoon [4]. Sericin is a polymer protein with a molecular weight ranging from 10 to over $300 \mathrm{kDa}$. Sericin has high contents of serine and aspartate, accounting for about $33.4 \%$ and $16.7 \%$, respectively [4]. Serine and aspartic acid have strong polar side chains. Thus, sericin can easily copolymerize and blend with other macromolecules to produce biocompatible materials with enhanced properties [5,6]. Sericin is considered to be one of the skin's important natural moisturizing factors due to its excellent hydrophilicity and hygroscopicity [7]. In addition, sericin has a great deal of excellent properties, such as biocompatibility, oxidation resistance, and anticoagulation [8]. The moisturizing property, the ability of promoting epithelial cell growth and oxidation resistance mean that sericin possesses great potential in biomedical applications. Silk-based materials have been attracting increasing interest for biomedical materials and tissue engineering applications in recent years. Chlapanidas et al. studied the biological properties of silk fibroin from 20 strains, and then picked the most promising strains in which sericin was developed for cosmetic and dermatological applications [9]. They also showed that sericin microspheres loaded with tumor necrosis factor- $\alpha$ (TNF- $\alpha$ ) blockers contribute to the down-regulation of cytokines [10]. In addition, a great deal of research on sericin and silk fibroin-based biomaterials, including the use of silk fibroin microspheres as a promoting wound healing material or a local coagulant [11-13], and sericin as a natural carrier for drug delivery, has been documented [14-16]. However, sericin contains a large amount of random coil structures, resulting in the formation of amorphous and brittle sericin materials which are not suitable for biomaterial application [17]. Therefore, sericin is usually cross-linked or blended with other polymers to enhance its mechanical performance. Agar is a macromolecular polysaccharide with hydrophilic, biocompatible and biodegradable ability [18]. In our previous study, we developed sericin/agar composite film modified with AgNPs to expand the application of sericin-based biomaterials $[19,20]$. AgNPs are synthesized with the assistance of ultraviolet (UV) light irradiation. However, long-term exposure under UV light may cause damage to sericin. Also, the aggregation of AgNPs on sericin is a major drawback of the UV-assisted method, as well as other methods currently available. In addition, the high-density synthesis of AgNPs is another key issue to be considered in the preparation of AgNPs functionalized materials. Recently, kinds of polymers such as poly (vinyl pyrrolidone) and polyamide network have been used as three-dimensional substrates for high-density growth of AgNPs [21,22]. However, most polymers are hydrophobic and not suitable for biomedical application. Therefore, it is important to find a substance which could not only improve the density of AgNPs, but also increase the hydrophilicity of the material surface for biomaterial application. Dopamine (DA) is a small molecule, and is the main component of viscous proteins secreted by mussels and can self-polymerize to polydopamine (PDA) under alkaline conditions and adhere to almost any substrate $[23,24]$. PDA contains several hydrophilic groups, such as $-\mathrm{OH},-\mathrm{COOH}$ and $-\mathrm{NH}_{2}$ [25]. PDA coating is an effective method used in recent years to improve the hydrophilicity and biocompatibility of materials [26,27]. PDA can not only provide sites for metal ions binding, but also reduce silver ions to AgNPs with its phenolic hydroxyl groups. PDA has been proved to be non-toxic to cells $[25,28]$. Thus, PDA is a very promising candidate for AgNPs synthesis. The issue of whether PDA can produce biologically active dopamine in vivo has not been well addressed in the literature on PDA-modified materials.

In this work, we utilized PDA to assist the synthesis of high-density AgNPs on the surface of PDA-SS/Agar film to yield AgNPs-PDA-SS/Agar film. Scanning electron microscopy (SEM), Fourier transform infrared spectroscopy (FT-IR), X-ray diffraction (XRD) confirmed the high-density synthesis of AgNPs on the surface of the blend film. In addition, the novel film exhibited excellent hydrophilicity and proper mechanical property. Antibacterial tests indicated that the fabricated film had excellent antibacterial activity against Escherichia coli (E. coli) and Staphylococcus aureus (S. aureus). Cell viability assay indicated the composite film had excellent cytocompatibility on the fibroblast $\mathrm{NIH} / 3 \mathrm{~T} 3$ cells. AgNPs-PDA-SS/Agar film shows great prospects in novel wound dressing, artificial skin, tissue engineering and antibacterial packaging. In addition, SS/Agar composite can be prepared 
into three-dimensional scaffold and gel materials to expand its application in bone repair and injectable hydrogel materials.

\section{Results and Discussion}

Here, we used PDA to direct the synthesis of the antibacterial AgNPs on the surface of PDA-coated SS/Agar film. The principle and procedure are briefly shown in Figure 1. The procedure of the preparation of the films is shown in Figure 1a. Agar solution $(2 \%, w / v)$ was added into sericin solution $(2 \%, w / v)$ to become sericin/Agar mixture, and then dried at $65{ }^{\circ} \mathrm{C}$ to form SS/Agar composite film. Next, dopamine hydrochloride powder was dissolved in Tris-HCl buffer ( $\mathrm{pH} 8.5$ ) to become $2 \%(w / v)$ polydopamine solution. Then, SS/Agar film was immersed into dopamine solution to produce PDA-coated SS / Agar film. Furthermore, PDA-SS/Agar film was soaked in $\mathrm{AgNO}_{3}$ solution at room temperature for $4 \mathrm{~h}$. The PDA layer acts as a secondary reaction platform, which can not only provide sites for metal ions binding, but also reduce silver ions to AgNPs with its phenolic hydroxyl groups to promote the synthesis of high-density AgNPs on the PDA-SS/Agar film. The prepared AgNPs-PDA-SS/Agar film was expected to have excellent antibacterial ability and cytocompatibility for wound dressing applications.

Figure $1 \mathrm{~b}$ shows the mechanism of dopamine polymerization and AgNPs synthesis with the assistance of PDA. First, dopamine was oxidized to form dopamine quinone, and then dopamine quinone was converted to leukodopaminechrome by cyclization. Leukodopaminechrome was oxidized to form dopaminechrome. Finally, dopaminechrome was transformed to PDA by means of rearrangement and polymerization. Almost all dopamine can be converted to PDA under alkaline conditions. PDA contains active phenolic hydroxyl groups, which can react with silver ions to reduce them to AgNPs.

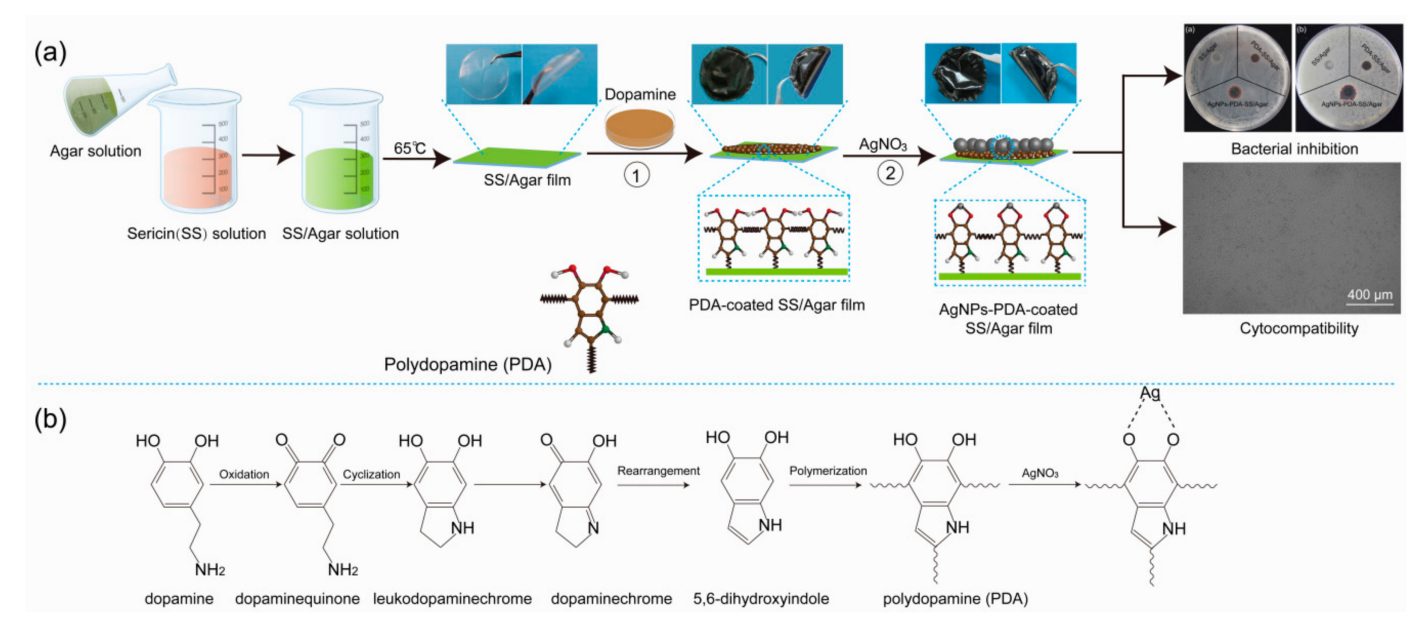

Figure 1. A diagram of the preparation of antibacterial AgNPs-PDA-SS/Agar film (a); schematic diagram of dopamine polymerization and AgNPs synthesis with the assistance of PDA (b).

\subsection{Scanning Electron Microscope (SEM), Energy Dispersive Spectroscopy (EDS)}

The SEM images of SS / Agar, PDA-SS / Agar, AgNPs-SS / Agar and AgNPs-PDA-SS / Agar films are shown in Figure 2. SS / Agar film exhibited a uniform and smooth surface (Figure 2a), indicating that sericin and agar were well blended. Figure $2 b$ shows the surface of PDA-SS/Agar film, which was covered with a layer of ridge-like substance. SS/Agar film was soaked into PDA solution at room temperature for $12 \mathrm{~h}$ to ensure PDA coating on its surface. Thus, we deduced that the ridge-like substance covering the surface of SS / Agar film was the coated PDA. Figure 2c shows the SEM image of AgNPs-SS/Agar film without PDA. High-density AgNPs (marked by red arrows) were observed in the SEM image of AgNPs-PDA-SS / Agar film (Figure 2d). The number of AgNPs in Figure 2d were much greater than in Figure 2c, which indirectly indicates the existence of PDA on the SS/Agar film, 
and suggests that PDA could effectively promote the synthesis of large amounts of AgNPs. Particle size analysis revealed that the size of the synthesized AgNPs was concentrated at 300-500 nm (Figure 2e). Most of the particles were spherical in shape. In some cases, AgNPs seemed to be merged, as the density of the particles was too high (Figure 2d). Furthermore, EDS confirmed the presence of silver in the AgNPs-PDA-SS / Agar composite film (Figure 2f).

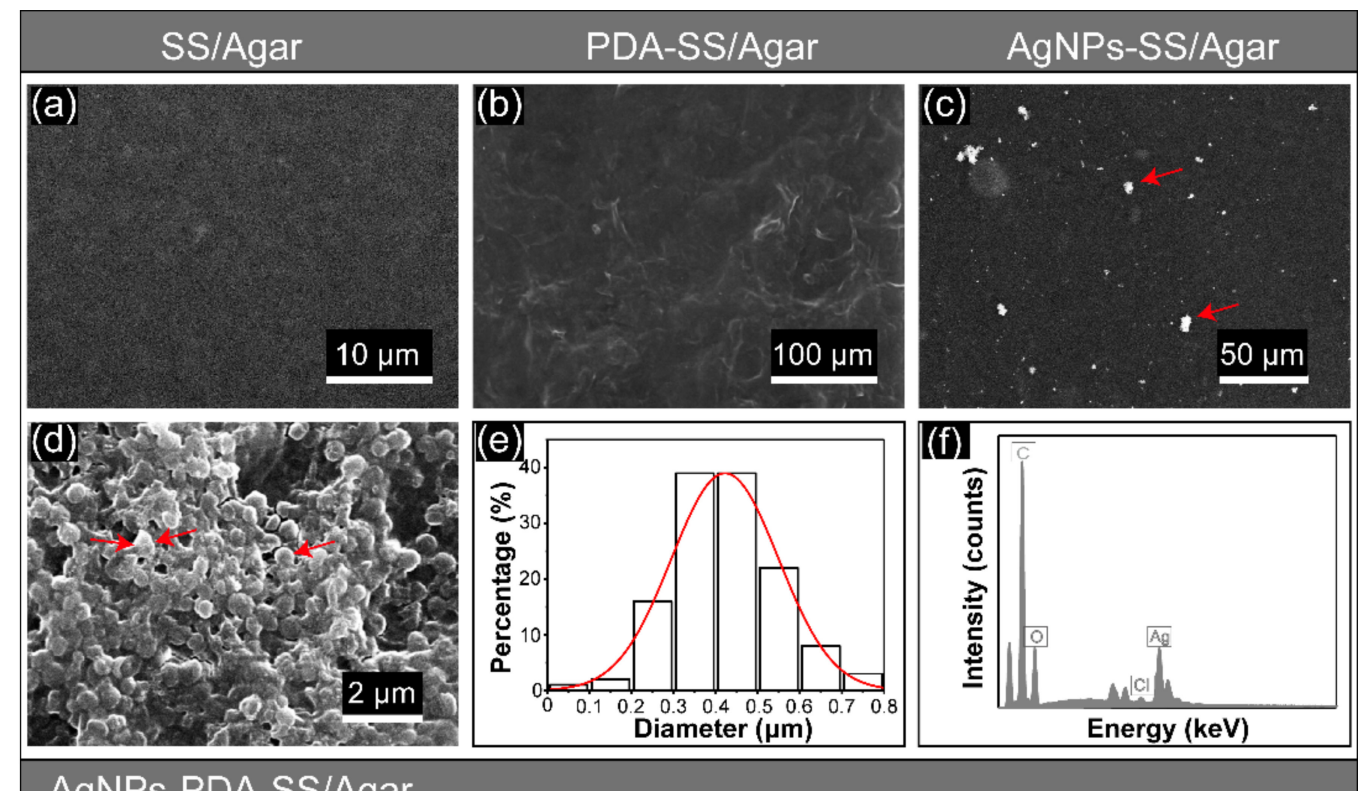

AgNPs-PDA-SS/Agar

Figure 2. Surface morphologies of SS/Agar (a); PDA-SS/Agar (b); AgNPs-SS/Agar (c); AgNPs-PDA-SS/Agar films (d); (e) is the particle size analysis of (d); EDS spectrum of AgNPs-PDA-SS/Agar film (f). Red arrows indicate high-density AgNPs.

\subsection{Fourier Transform Infrared Spectroscopy (FT-IR)}

FT-IR spectra were collected to characterize the structure of different films. The results are shown in Figure 3. The peaks that appeared at $1037 \mathrm{~cm}^{-1}$ and $926 \mathrm{~cm}^{-1}$ in agar film were characteristic peaks of agar, corresponding to the $\mathrm{C}=\mathrm{O}$ stretching vibration of 3,6-anhydrogalactose [29]. The two characteristic peaks at 1614 and $1516 \mathrm{~cm}^{-1}$ in the sericin film corresponded to amid I and II [30], respectively. Four characteristic peaks at 926, 1037, 1516 and $1614 \mathrm{~cm}^{-1}$ occurred in the spectra of SS/Agar, PDA-SS/Agar and AgNPs-PDA-SS/Agar films, indicating the presence of sericin and agar in the blend films, and that the structure of sericin and agar was not affected after blending. After PDA coating, two additional characteristic peaks at 1510 and $1601 \mathrm{~cm}^{-1}$ were observed in the spectra of PDA-SS / Agar and AgNPs-PDA-SS / Agar films, which corresponded to the $\mathrm{C}=\mathrm{C}$ stretching and $\mathrm{N}-\mathrm{H}$ bending vibrations of the indoline or indole structures in PDA, respectively [31,32]. The appearance of these two peaks demonstrated the successful PDA coating on the SS/Agar film, which was consistent with the observation of SEM (Figure 2b). The spectra of AgNPs-PDA-SS/Agar film showed similar characteristic peaks of sericin and agar with that of SS/Agar film, but differed from that of PDA-SS/Agar film. The possible reason was that the characteristic peak of PDA was close to that of sericin; thus, PDA coating affected the characteristic peaks of sericin and agar, and resulted in the change of SS/Agar spectrum. However, when PDA was used to reduce $\mathrm{Ag}^{+}$to AgNPs, the structure of PDA was changed; thus, the characteristic peak of PDA disappeared and could no longer affect the characteristic peaks of sericin and agar. AgNPs alone did not affect the structure of sericin and agar, and could not change the spectrum of SS/Agar film. 


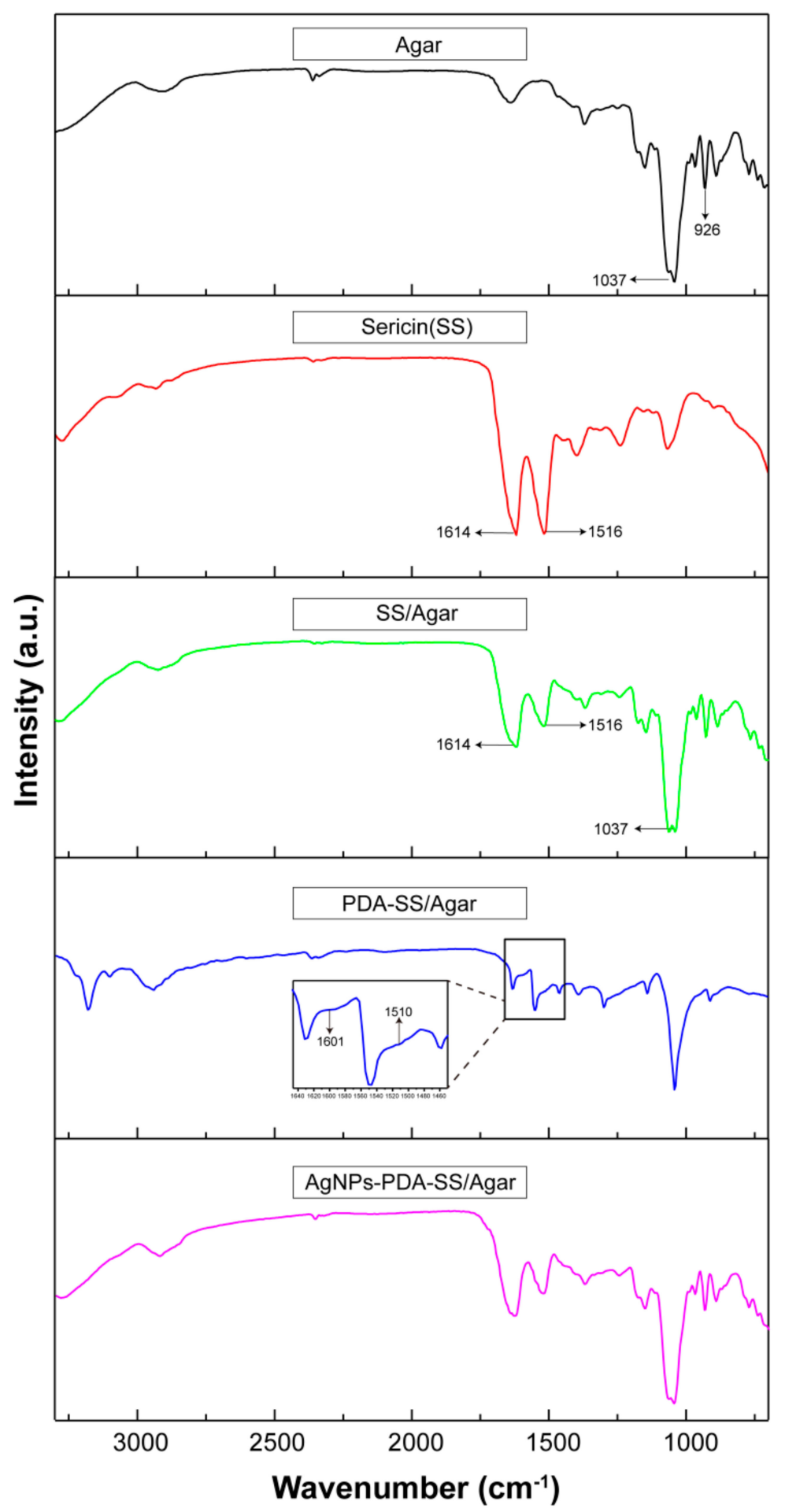

Figure 3. FT-IR spectra of Agar, Sericin (SS), SS/Agar, PDA-SS/Agar and AgNPs-PDA-SS/Agar films.

\subsection{X-ray Diffraction (XRD)}

The XRD patterns of AgNPs-PDA-SS / Agar, PDA-SS/Agar, SS/Agar, sericin and agar films are shown in Figure 4 . The peak located at $2 \theta=19.2^{\circ}$ corresponded to the silk II structure of sericin protein. The peak at $2 \theta=14.9^{\circ}$ was the characteristic peak of agar [33]. The peak at $2 \theta=13.3^{\circ}$ appeared in all XRD patterns except sericin, and was ascribed to the characteristic peak of agar with a slight deviation. The peak at $2 \theta=20.3^{\circ}$ appeared in all composite films, which may be due to the deviation of the characteristic peak of silk II at $2 \theta=19.3^{\circ}$ after blending with agar [34]. Our results showed that the 
blending of sericin and agar slightly changed the characteristic peak of agar and sericin. After PDA coating, the XRD patterns of SS / Agar film did not change, indicating that PDA did not affect the crystal structure of sericin and agar. The diffraction peak at $38.1^{\circ}$ and $32.4^{\circ}$ could be assigned to the (111) and (122) planes of the face-centered cubic structure of Ag [35,36], demonstrating the presence of AgNPs in the AgNPs-PDA-SS/Agar film.

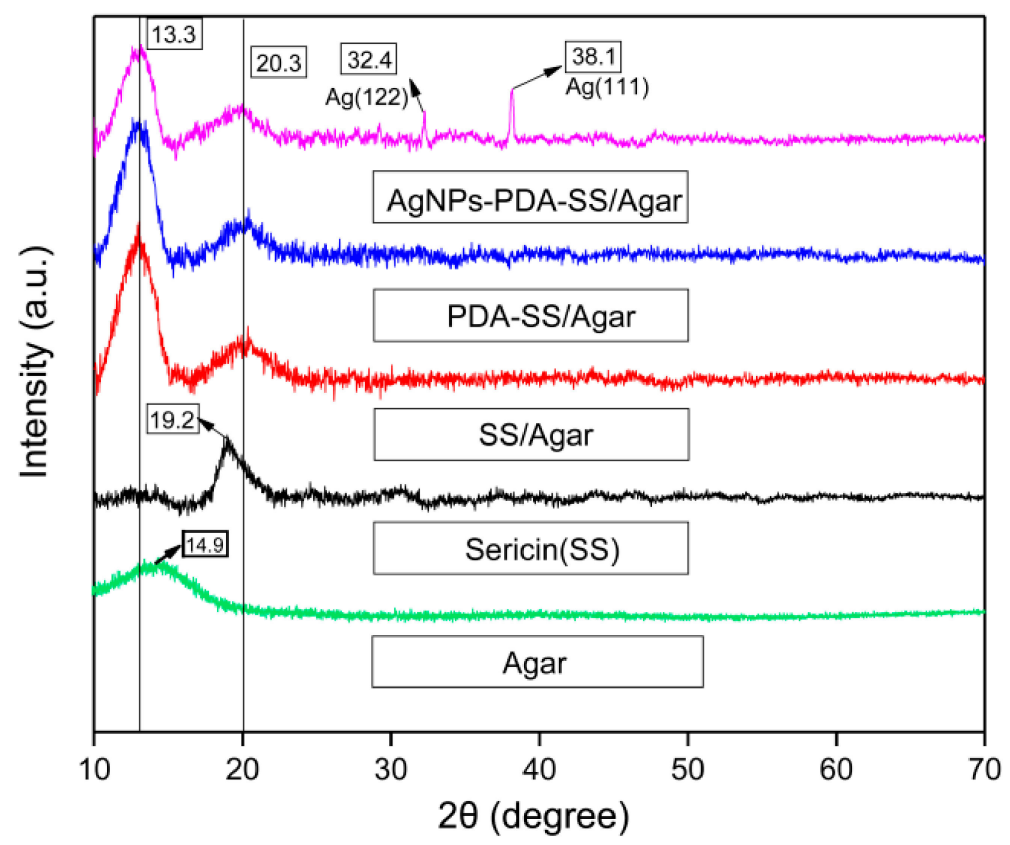

Figure 4. XRD patterns of Agar, Sericin (SS), SS/Agar, PDA-SS/Agar and AgNPs-PDA-SS/Agar films.

\subsection{Wettability and Water Uptake Ability}

The water contact angle of SS/Agar, PDA-SS/Agar and AgNPs-PDA-SS / Agar films are shown in Figure 5. The water contact angle of SS/Agar was $78.4^{\circ}$, indicating the surface of SS/Agar was hydrophilic. After PDA coating, the water contact angle decreased to $62.3^{\circ}$, indicating that the wettability of the composite film increased. Figure $5 c$ shows that the water contact angle of AgNPs-PDA-SS/Agar film was $81.3^{\circ}$, suggesting AgNPs modification slightly reduced the wettability of the material surface. The reason may be AgNPs are hydrophobic substances, and the uniform distribution of AgNPs on the PDA-SS / Agar composite film would reduce the hydrophilicity of the film. The water contact angle of AgNPs-PDA-SS/Agar film was still less than $90^{\circ}$, indicating that the prepared material was hydrophilic and potentially useful for biomaterial application.

To further explain the hydrophilicity, the swelling property of the material was tested, as illustrated in Figure 5d,e. The result showed the swelling of AgNPs-PDA-SS/Agar, PDA-SS/Agar and SS/Agar films in 60 seconds. It is obvious that in two seconds, the composite film absorbed a lot of water, indicating that the surface of the composite film had excellent hydrophilicity. The water absorption capacity of PDA-SS / Agar film in a short period of time was better than that of AgNPs-PDA-SS / Agar and SS / Agar films. After 12-48 h, the swelling ratios of different films were in the range of $150 \%$ to $250 \%$ (Figure 5e), indicating that the prepared film had excellent water uptake ability. According to the moist wound healing theory, moisture promotes wound healing, reduces the pain of dressing removal and scarring and does not destroy freshly formed tissue. Therefore, the excellent hydrophilicity and wetting properties of the prepared composite film are advantageous for wound dressing or other potential biomedical applications. 

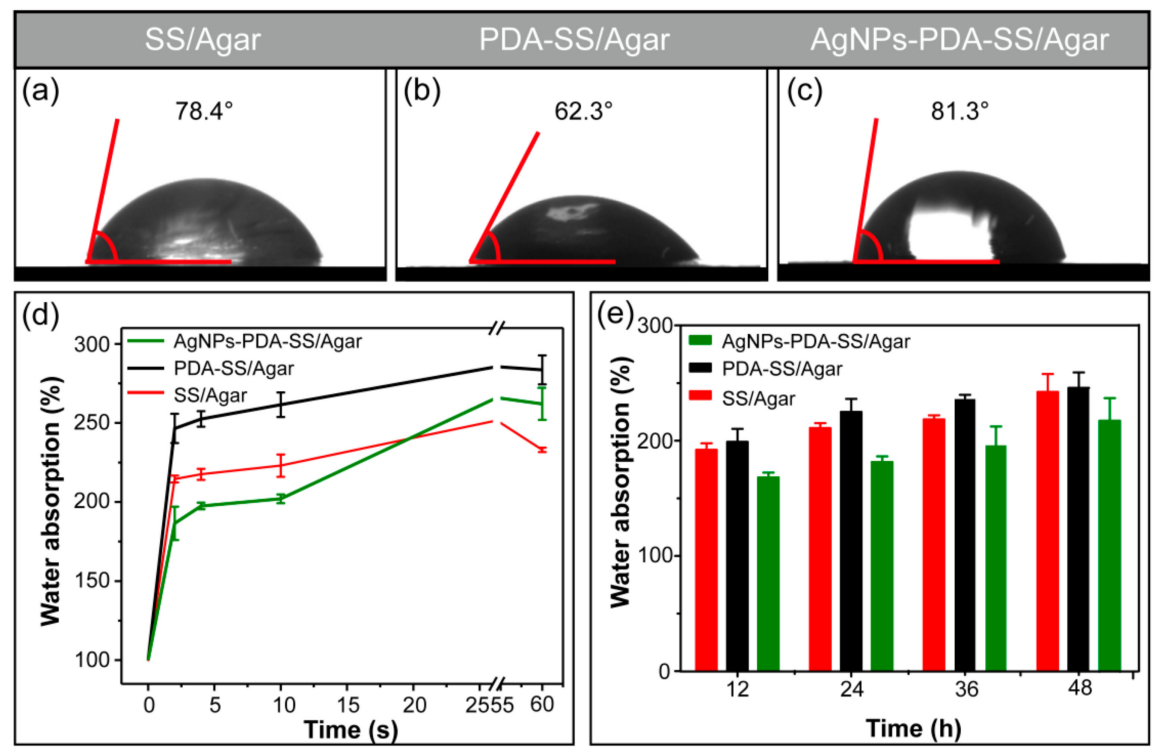

Figure 5. Water contact angle of SS/Agar (a), PDA-SS/Agar (b), AgNPs-PDA-SS/Agar films (c) and water absorption of different films $(\mathbf{d}, \mathbf{e})$.

\subsection{Mechanical Properties}

Figure 6a,b shows that SS/Agar and PDA-SS/Agar films had tensile strength exceeding $40 \mathrm{MPa}$. It is known that sericin is fragile and lacks mechanical properties, while agar has high tensile strength [37]. Therefore, the blending of sericin and agar improved the tensile strength of sericin film. The incorporation of AgNPs into PDA-SS/Agar film resulted in the reduction of tensile strength to about $25 \mathrm{MPa}$, when compared with SS/Agar and PDA-SS/Agar films. This may be because the synthesis of AgNPs on the PDA-SS/Agar film increased the film's thickness and roughness, which resulted in a reduction in tensile strength. However, this strength was still competent for some applications such as wound caring and food packaging. Elongation at break reflects the flexibility of a material [38]. The elongation at break of SS/Agar was less than 5\%. PDA coating increased the elongation at break of SS / Agar film to about 7\%, probably due to an increase in the thickness of the composite film. Compared with PDA-SS/Agar film, the elongation at break of AgNPs-PDA-SS/Agar film slightly increased to $8 \%$, indicating the enhanced flexibility of AgNPs-PDA-SS/Agar film. Similarly, thickness and roughness were likely responsible for the increase of the elongation at break of AgNPs- PDA-SS/Agar film. The flexible nature of AgNPs-PDA-SS/Agar film would be beneficial for wound dressing and other potential applications.
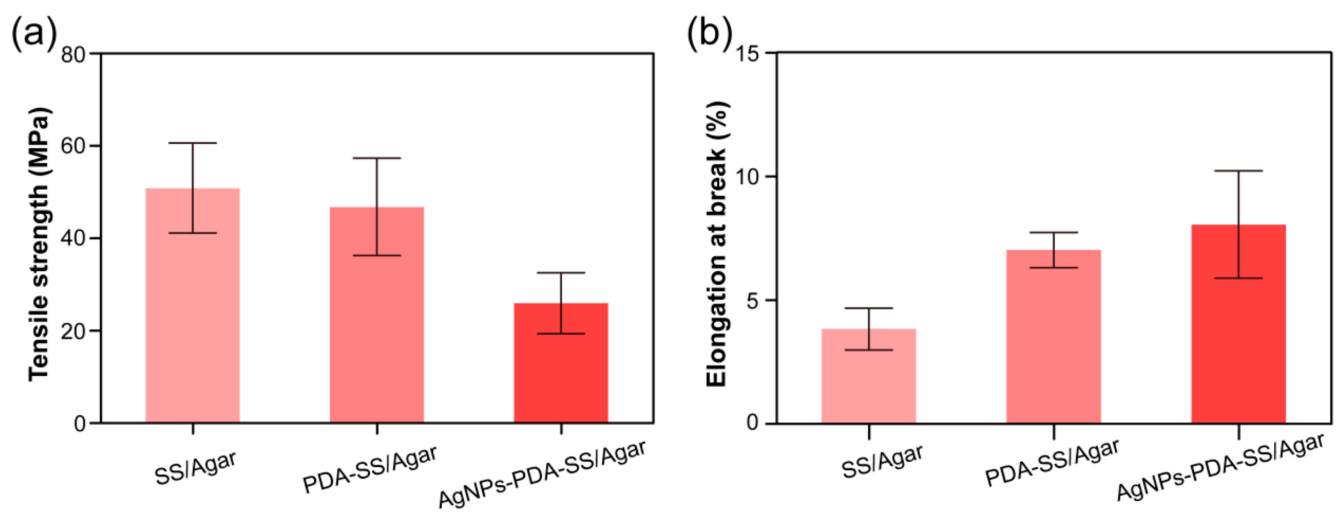

Figure 6. Mechanical properties of different films: (a) tensile strength, and (b) elongation at break. 


\subsection{Inhibition Zone Assay}

Bacterial infection impedes wound healing. So antibacterial ability is necessary for wound dressing. Figure 7 shows the inhibition zones of AgNPs and PDA-modified or unmodified SS/Agar film against two common bacteria found in wound infections (S. aureus, E. coli). No inhibition zone appeared for SS / Agar and PDA-SS/Agar films toward the two types of bacteria. An obvious inhibition zone occurred in the presence of AgNPs-PDA-SS/Agar film toward E. coli and S. aureus, demonstrating that the fabricated AgNPs-PDA-SS/Agar film had excellent antibacterial ability. The diameters of the inhibition zones are shown in Table 1.
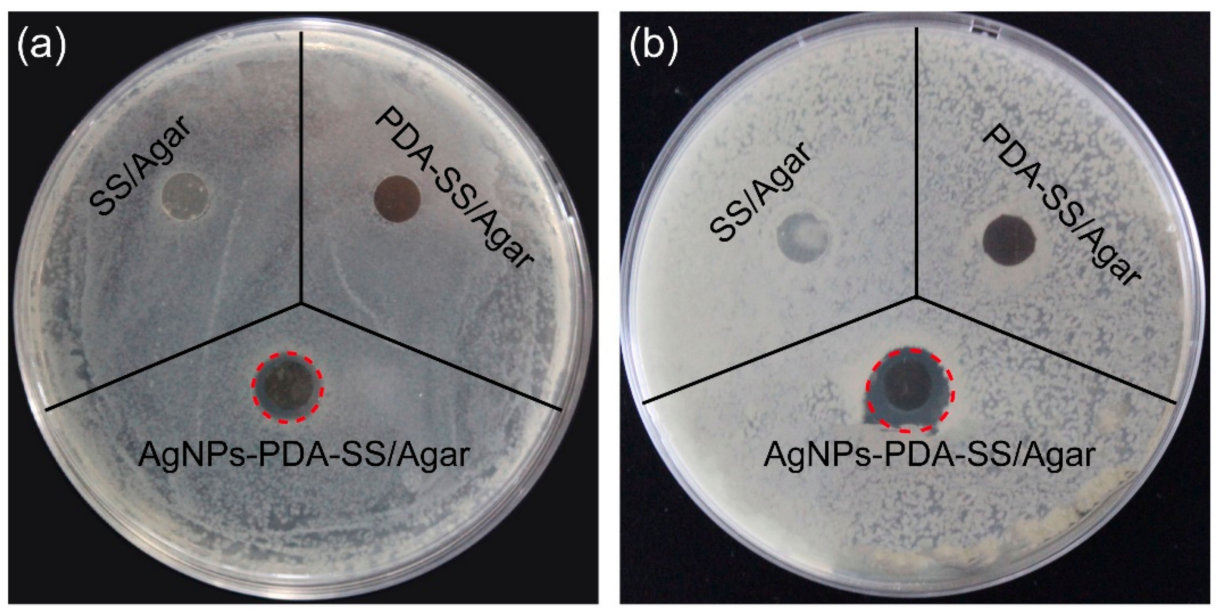

Figure 7. The inhibition zones of SS / Agar, PDA-SS/Agar, AgNPs-PDA-SS/Agar films against E. coli (a) and $S$. aureus (b). Red dotted circle represents the edge of the inhibition zone.

Table 1. Diameters of the inhibition zones of SS/Agar, PDA-SS/Agar and AgNPs-PDA-SS/Agar films against $E$. coli (a) and S. aureus (b).

\begin{tabular}{cccc}
\hline Bacteria & SS/Agar $(\mathbf{c m})$ & PDA-SS/Agar $(\mathbf{c m})$ & AgNPs-PDA-SS/Agar $(\mathrm{cm})$ \\
\hline E. coli & $1.10 \pm 0.00$ & $1.10 \pm 0.00$ & $1.63 \pm 0.03$ \\
S. aureus & $1.10 \pm 0.00$ & $1.10 \pm 0.00$ & $1.91 \pm 0.11$ \\
\hline
\end{tabular}

\subsection{Bacterial Growth Curve}

A bacterial growth curve experiment was carried out to assess the inhibition effect of AgNPs and PDA treated and untreated SS/Agar film on bacterial growth. Figure 8 shows the growth curves of E. coli (Figure 8a) and S. aureus (Figure 8b) in the presence of different films, respectively. The growth of E. coli and S. aureus in the presence of SS/Agar and PDA-SS/Agar films was similar to the control, indicating that SS/Agar and PDA-SS/Agar films did not have bacteriostatic activity. Compared with the control, AgNPs-PDA-SS / Agar significantly inhibited bacterial growth up to $20 \mathrm{~h}$, suggesting that AgNPs-PDA-SS/Agar film had a long-term and efficient inhibition effect on bacterial growth.

\subsection{Antimicrobial Stability}

AgNPs-PDA-SS/Agar film was treated at different $\mathrm{pH}(4.0,7.4,10.0)$ for $24 \mathrm{~h}$, and then the inhibitory effect of the treated film against E. coli and S. aureus was determined. As shown in Figure 8c,d, in the absence of AgNPs, there was no significant difference in bacterial growth between SS / Agar and the control at different time points, indicating SS/Agar film had no bacteriostasis ability. Compared with the control, the bacterial growth was obviously inhibited in the presence of AgNPs-PDA-SS/Agar film after treatment with different $\mathrm{pH}$, suggesting AgNPs-PDA-SS/Agar film had stable and long-term antibacterial ability, which was advantageous for wound dressing and other potential applications. 
(a) 2

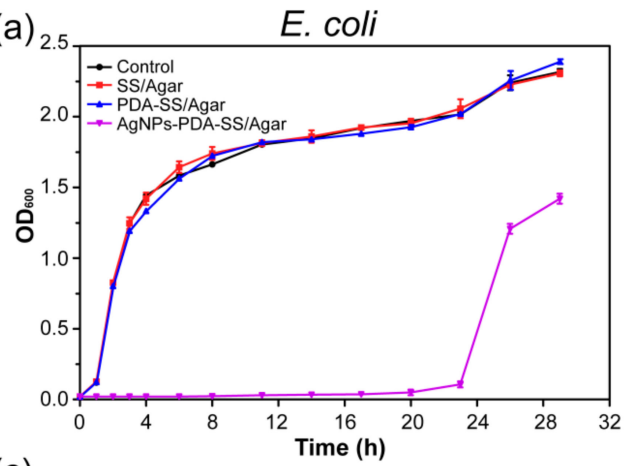

(c)

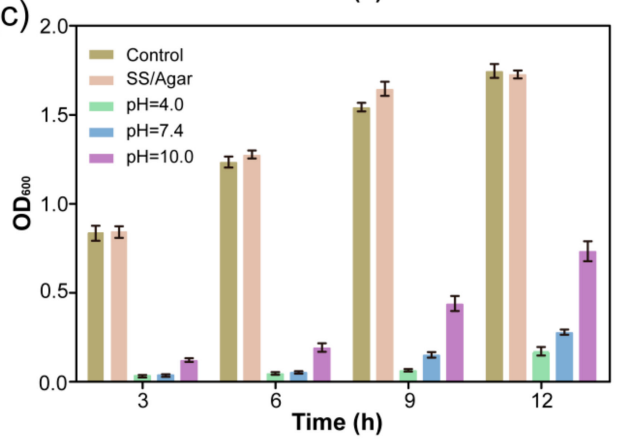

(b)

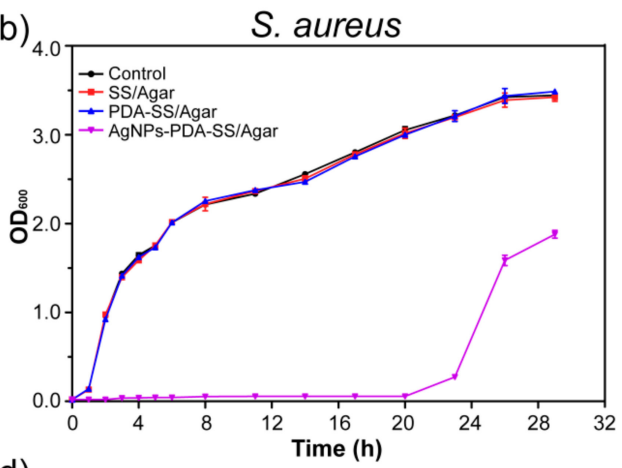

(d)

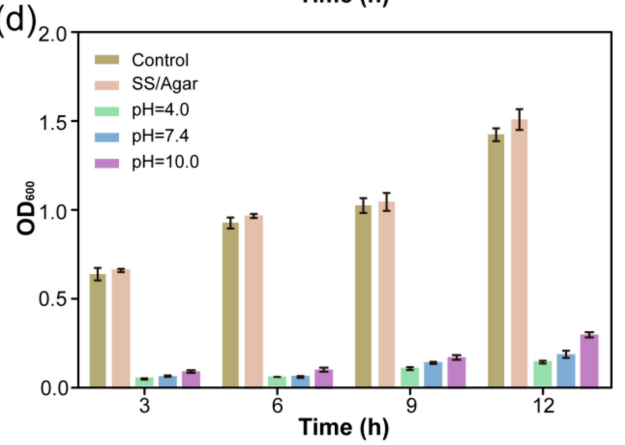

Figure 8. Bacterial growth curve of E. coli (a) and S. aureus (b) in the presence of different films, and antimicrobial stability analysis of AgNPs-PDA-SS/Agar film under different $\mathrm{pH}$ conditions (c,d).

\subsection{Cytocompatibility}

To evaluate the cytotoxicity of SS/Agar, PDA-SS/Agar and AgNPs-PDA-SS/Agar films, cell counting kit-8 (CCK-8) assay was performed to examine the cells treated with different films. In the test, the metabolically active cells react with the tetrazolium salt in the CCK-8 solution to produce a soluble formaldehyde nitrogen dye with maximum absorbance at $450 \mathrm{~nm}$ [39]. Optical density (OD) reflects cell survival and living cells [40]. The results showed there was no significant difference in cell viability between the control and the experimental group treated with AgNPs-PDA-SS/Agar film (Figure 9). Notably, the cell viability when treated with PDA-SS/Agar film was higher than that of the control, indicating PDA was not only non-toxic on cells, but also could promote cell proliferation to improve cell viability. In addition, the cell morphology under different treatments almost did not change after $24 \mathrm{~h}$ (Figure 10), suggesting that the prepared films had excellent cytocompatibility on the fibroblast NIH/3T3 cells, which is beneficial for its application in biomaterials.

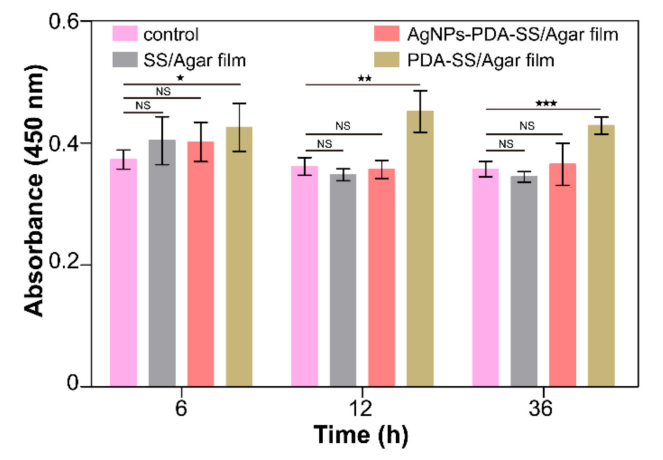

Figure 9. CCK-8 assay of the cytocompatibility of different films on NIH/3T3 cells. The statically significant values are expressed by “NS" (not significant), “ $\star$ " $(p<0.05)$, “ $\star \star$ " $(p<0.01)$ and “ $\star \star \star$ ” $(p<0.001)$. 


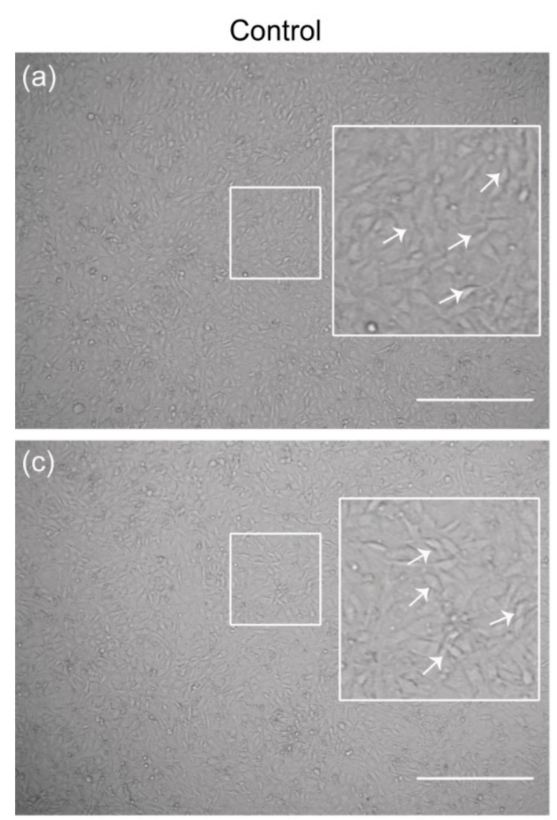

PDA-SS/Agar film
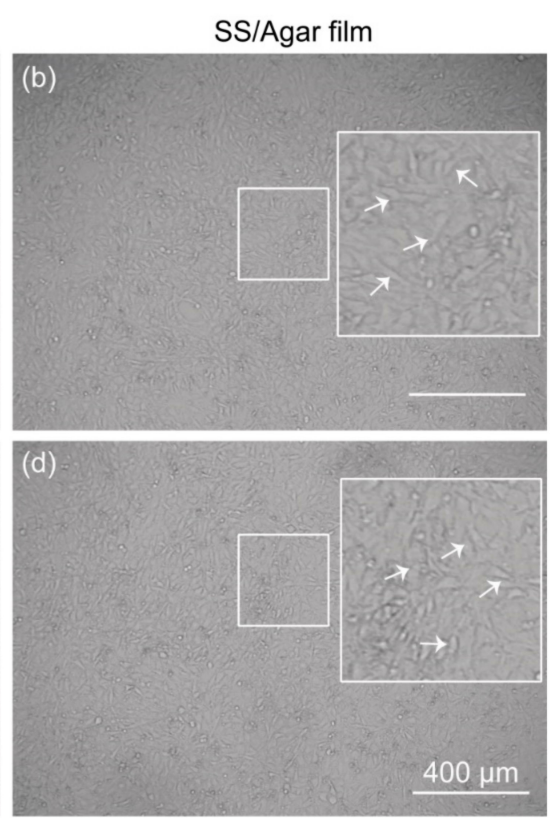

AgNPs-PDA-SS/Agar film

Figure 10. Microscopic observation of NIH/3T3 cells morphology with control (a), in the presence of SS/Agar film (b), PDA-SS/Agar film (c) and AgNPs-PDA-SS/Agar film (d). Small box represents a selected area, big box represents the enlarged image in the small box. White arrows indicate the observed fibroblast NIH/3T3 cells. The scale bar is $400 \mu \mathrm{m}$.

To better visualize the effects of the prepared films on NIH/3T3 cells viability, a living/dead cell staining assay was performed. In this assay, living cells are stained green, while dead cells are red. After being treated with different films for $24 \mathrm{~h}$, the fluorescence images clearly showed almost all cells were stained green, a very few cells $(<1 \%$ ) were stained red (marked with white arrows, Figure 11), indicating the excellent cytocompatibility of the films on NIH/3T3 cells. This result was in good agreement with that of CCK-8 assay and the microscopic observation on cell morphology.

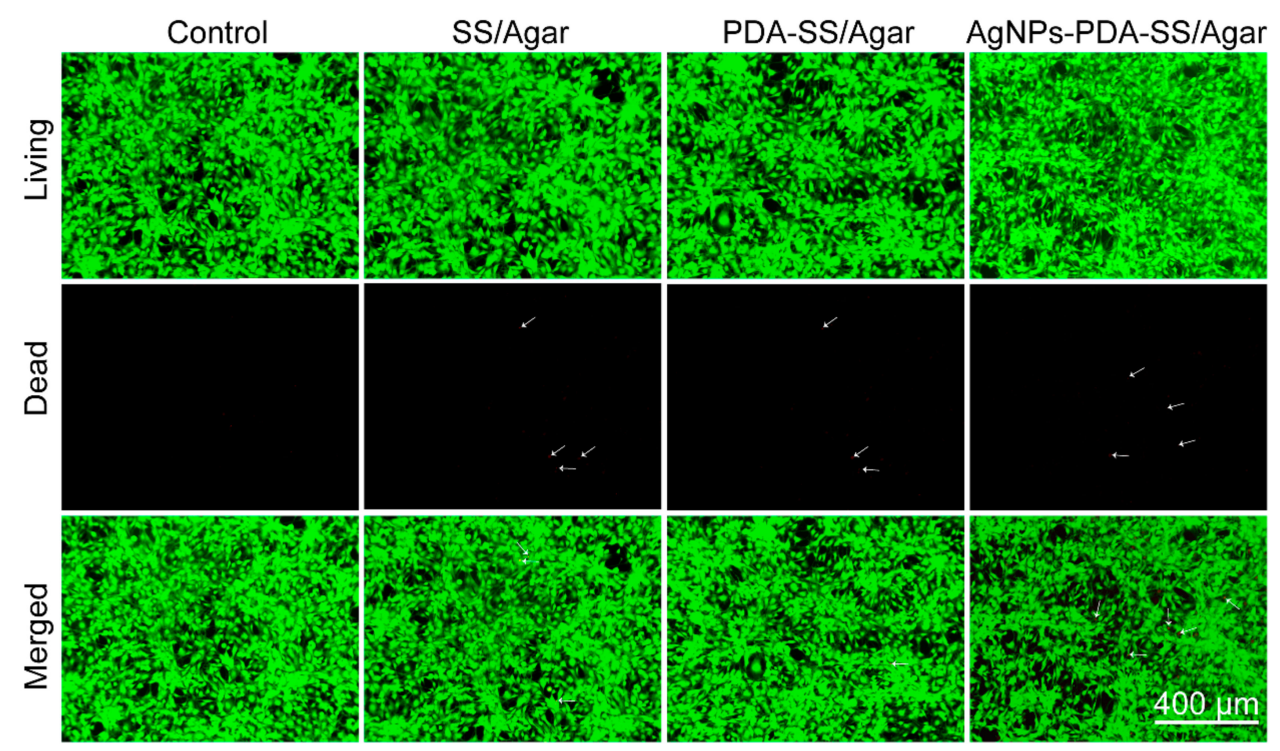

Figure 11. Living/dead cell staining assay of NIH/3T3 cells after being treated with different films. White arrows indicate a very few cells $(<1 \%$ ) were stained red. 


\section{Materials and Methods}

\subsection{Materials and Chemicals}

The strain of silkworm we used in this work was a commercial silkworm strain 872. Silkworms were reared in our laboratory with fresh mulberry leaves at $25^{\circ} \mathrm{C}$ and $75 \%$ relative humidity under $12 \mathrm{~h}$ photoperiod. Fresh silkworm cocoons were collected for sericin preparation. Dopamine hydrochloride and silver nitrate $\left(\mathrm{AgNO}_{3}\right)$ were purchased from Aladdin (Shanghai, China). Hydrochloric acid and Tris (hydroxymethyl) aminomethane (Tris) were from Sangon Biotech (Shanghai, China). Ultrapure water made by a MilliQ water purification system (Millipore, Billerica, MA, USA) was used in the experiment. The Cell counting kit-8 (CCK-8) used in the experiment was bought from Beyotime (Beijing, China). LIVE/DEAD cell viability kit was bought from Thermo Fisher Scientific (Waltham, MA, USA). NIH3T3 (mouse embryonic fibroblast) cell lines were received from the China Infrastructure of Cell Line Resources. The Dulbecco's modified Eagle's medium (DMEM), Penicillin/Streptomycin, Fetal Bovine Serum (FBS), and Trypsin-EDTA were bought from Gibco BRL (Gaithersburg, MD, USA).

\subsection{Preparation of AgNPs-PDA-SS/Agar Film}

Sericin was obtained from silkworm cocoons through high temperature. Silkworm cocoons were cut into pieces and treated at $121{ }^{\circ} \mathrm{C}$ and $0.1 \mathrm{MPa}$ for $15 \mathrm{~min}$. Then, sericin was extracted into solution and separated from silk fibroin by filtration, which is descripted in our previous report [41-43]. Agar was dissolved in water with agitation at $90{ }^{\circ} \mathrm{C}$ to a final concentration of $2 \%(w / v)$. Sericin solution $(2 \%, w / v)$ and agar solution $(2 \%, w / v)$ were well mixed as a ratio of $1: 1$ at $60{ }^{\circ} \mathrm{C}$. Subsequently, the mixture was dried at $65^{\circ} \mathrm{C}$ overnight to form SS / Agar film. Next, dopamine hydrochloride was dissolved in Tris- $\mathrm{HCl}$ buffer ( $\mathrm{pH}$ 8.5) to form polydopamine solution $(2 \%, w / v)$, the chemical process was shown in Figure 1b. SS/Agar film was directly placed in freshly prepared polydopamine solution with stirring at $37^{\circ} \mathrm{C}$ for $12 \mathrm{~h}$. Then, the PDA-treated blend film was removed, washed by water for three times, and dried at $25^{\circ} \mathrm{C}$ for $12 \mathrm{~h}$ to obtain PDA-coated SS/Agar composite film. Next, PDA-SS / Agar film was immersed into $\mathrm{AgNO}_{3}$ solution $(10 \mathrm{mM})$ at $25^{\circ} \mathrm{C}$ for $4 \mathrm{~h}$. After multiple washes, the film was dried at $25^{\circ} \mathrm{C}$ to yield AgNPs modified PDA-SS/Agar film. The average thickness of the SS/Agar, PDA-SS / Agar and AgNPs-PDA-SS/Agar films determined by microscope were $145.47 \mu \mathrm{m}$, $153.29 \mu \mathrm{m}$ and $158.90 \mu \mathrm{m}$, respectively.

\subsection{Material Characteristics}

The surface morphologies of SS / Agar, PDA-SS / Agar, AgNPs-SS/Agar and AgNPs-PDA-SS/Agar films were characterized by JEOL scanning electron microscopy JSM-6510LV (Tokyo, Japan). The films were cut into strips with a dimension of $1 \mathrm{~cm} \times 1 \mathrm{~cm}$ (length $\times$ width), dried, and sputtered with gold prior to SEM test. The accelerating voltage for the test was $20 \mathrm{kV}$. The working distance was 10 $\mathrm{mm}$. Energy dispersive spectra (EDS) were collected on Oxford INCA X-Max 250 (Abingdon, UK) during SEM test to analyze the chemical elements. XRD spectra were recorded on PANalytical $x^{\prime}$ pert (Almelo, Netherland) within 10-80 . Nicolet iz10 FT-IR spectrometer (Thermofisher Scientific, Waltham, MA, USA) was used to obtain FT-IR spectra in the wavenumber of $4000-800 \mathrm{~cm}^{-1}$.

\subsection{Hydrophilicity}

The hydrophilicity of the prepared films was measured by surveying the sessile drip contact angle using a KRÜSS DSA100 contact angle analyzer (Hamburg, Germany) at $25^{\circ} \mathrm{C}$. Water droplets $(4 \mu \mathrm{L})$ were dispensed on the surface of the film and the water contact angle was measured. Five points are measured for each sample and averaged. 


\subsection{Water Absorption Ratio and Moisture Retention Capacity}

Water absorption ratio was used to characterize the swelling property of the film. The dry films $(3 \mathrm{~cm} \times 3 \mathrm{~cm}$, length $\times$ width) were weighed, and then immersed into water. Afterwards, the swollen samples were removed from water at different intervals and weighed after the removal of water on the surface by filter paper. Swelling property was defined as follows:

$$
\text { Water absorption ratio }(\%)=\left(\mathrm{m}_{2}-\mathrm{m}_{1}\right) / \mathrm{m}_{1} \times 100 \%
$$

where $m_{1}$ and $m_{2}$ were the weights of dry and swollen films, respectively. Three replications per sample were made to ensure the accuracy of the experiment.

\subsection{Mechanical Properties}

For film materials, the tensile strength and elongation at break are two common indicators for mechanical properties. The tensile strength and elongation at break of the films were studied by SHIMADZU AG-X plus (Tokyo, Japan), which is a common instrument for mechanical properties analysis. For the test, the films with a dimension of $4 \mathrm{~cm} \times 1 \mathrm{~cm}$ (length $\times$ width) were measured with a crosshead speed of $3 \mathrm{~mm} / \mathrm{min}$. The length and width of the samples were determined according to the mold we used, and the stretching rate was suggested by the manufacturer's protocol and validated by previous reports [44-46]. At least 8 replicates of an individual film were examined.

\subsection{Inhibition Zone Assay}

The method presented by Schillinger and Lücke was applied to test anti-bacterial inhibition zone of the prepared films [47]. Briefly, E. coli and S. aureus were inoculated into Luria-bertani (LB) medium (pH 7.4) with shaking at $37^{\circ} \mathrm{C}$ until optical density (OD) value at $600 \mathrm{~nm}\left(\mathrm{OD}_{600}\right)$ reached 1.0. Then, bacterial suspension $(200 \mu \mathrm{L})$ was uniformly spread on agar plate in the presence of SS / Agar, PDA-SS-SS/Agar and AgNPs-PDA-SS-SS/Agar films and incubated at $37{ }^{\circ} \mathrm{C}$ for $24 \mathrm{~h}$. The diameters of inhibition zone around the samples were measured.

\subsection{Growth Curve Assay}

The growth curve analysis was carried out based on Pal's protocol [48]. Bacteria were inoculated into LB medium and cultured at $37^{\circ} \mathrm{C}$ with constant shaking $(220 \mathrm{rpm})$ in the presence of different films. Then, bacterial suspension $(0.5 \mathrm{~mL})$ was collected at different time intervals to measure $\mathrm{OD}_{600}$. All samples were tested in triplicate.

\subsection{Antimicrobial Stability}

To test the antibacterial stability of AgNPs-PDA-SS/Agar film, the films $(1 \mathrm{~cm} \times 1 \mathrm{~cm}$, length $\times$ width) were soaked in PBS buffers ( $\mathrm{pH} 4.0,7.4,10.0)$. After $24 \mathrm{~h}$, the films were dried at $25{ }^{\circ} \mathrm{C}$ and then added into $10 \mathrm{~mL}$ bacterial suspensions with the same initial $\mathrm{OD}_{600}$. Bacterial suspensions $(0.5 \mathrm{~mL})$ were collected at different intervals and $\mathrm{OD}_{600}$ was measured to determine the antibacterial stability of the prepared films.

\subsection{Cytotoxicity}

The fibroblast NIH/3T3 cells were cultured in Dulbecco's modified eagle medium at $37^{\circ} \mathrm{C}$ with $5 \% \mathrm{CO}_{2}$ and $95 \%$ relative humidity. Prior to the cytotoxicity test, the circular SS/Agar, PDA-SS/Agar and AgNPs-PDA-SS / Agar films (diameter $=7 \mathrm{~mm}$ ) were irradiated by UV light overnight to ensure the sterility of the materials. NIH/3T3 cells $(100 \mu \mathrm{L})$ were loaded in a 96-well plate at a density of $1 \times 10^{4}$ cells/well and incubated at $37^{\circ} \mathrm{C}$ for $12 \mathrm{~h}$ in the presence of the sterile films. Untreated cells were set as controls. CCK-8 kit was used to detect cells viability after treated with different films. After various time, the films were removed from the medium, and CCK-8 solution $(10 \mu \mathrm{L})$ was added 
into each well and incubated at $37^{\circ} \mathrm{C}$. After $1 \mathrm{~h}$, the optical density (OD) were measured at $450 \mathrm{~nm}$ on a Tecan Infinite M200 Pro microplate reader (Männedorf, Switzerland). Cell viability was the percentage of OD values in the treated and control groups. Each experimental group was tested for at least three replications. After culture for $24 \mathrm{~h}$, NIH/3T3 cells morphology were observed on a fluorescence microscope.

In addition, a living/dead cells staining assay was performed to further assess the effect of the films on NIH/3T3 cells. NIH/3T3 cells were cultured at $37^{\circ} \mathrm{C}$ as mentioned above. After being treated with SS/Agar, PDA-SS/Agar and AgNPs-PDA-SS/Agar films for $24 \mathrm{~h}$, the staining solution $(30 \mu \mathrm{L})$ was added into each well and incubated with the cells at $37^{\circ} \mathrm{C}$ for $15 \mathrm{~min}$. The fluorescence images were recorded on an Invitrogen EVOS FL Auto Cell Imaging System (Waltham, MA, USA). Each sample was tested in triplicate.

\subsection{Statistics}

All experiments were performed at least in triplicate, and the results were presented as average \pm standard deviation (SD). Student's $t$-test, together with variance analysis, was carried out to determine the statistical significance between two groups. The statically significant values were expressed by “ $\star$ " $(p<0.05)$, “ $\star \star "(p<0.01)$ and “ $\star \star \star$ ” $(p<0.001)$.

\section{Conclusions}

In this study, we successfully synthesize high-density AgNPs on PDA-SS / Agar composite film with the assistance of PDA. AgNPs-PDA-SS/Agar composite film exhibits good hydrophilicity and proper mechanical properties. In addition, AgNPs-PDA-SS/Agar film has high efficiency and durable antibacterial ability, and excellent compatibility on the fibroblast NIH/3T3 cells. These excellent properties facilitate the potential applications of AgNPs-PDA-SS/Agar film in wound dressing, tissue engineering and antibacterial packaging.

Author Contributions: L.L., Y.W. and H.H. conceived and designed the experiments; L.L., R.C., G.T., L.A., M.Y. and P.W. performed the experiments; L.L., R.C. and G.T. analyzed the data; H.Z. and P.Z. contributed reagents/materials/analysis tools; L.L. wrote the draft; Y.W. and H.H. supervised the research and revised the manuscript.

Funding: This research was funded by National Natural Science Foundation of China (grant number 31572465), Chongqing Research Program of Basic Research, Frontier Technology (grant number cstc2015jcyjBX0035), State Key Program of the National Natural Science of China (grant number 31530071), Fundamental Research Funds for the Central Universities (grant number XDJK2018B010, XDJK2018C063), Graduate Research and Innovation Project of Chongqing (grant number CYB17069, CYS18123) and Open Project Program of Chongqing Engineering and Technology Research Center for Novel Silk Materials (grant number silkgczx2016003).

Conflicts of Interest: The authors declare no conflict of interest. The founding sponsors had no role in the design of the study; in the collection, analyses, or interpretation of data; in the writing of the manuscript, and in the decision to publish the results.

\section{References}

1. Ouattar, B.; Simard, R.E.; Piett, G.; Bégin, A.; Holley, R.A. Inhibition of surface spoilage bacteria in processed meats by application of antimicrobial films prepared with chitosan. Int. J. Food. Microbiol. 2000, 62, 139-148. [CrossRef]

2. Sondi, I.; Salopeksondi, B. Silver nanoparticles as antimicrobial agent: A case study on E. Coli as a model for gram-negative bacteria. J. Colloid Interf. Sci. 2004, 275, 177-182. [CrossRef] [PubMed]

3. Huang, L.; Zhao, S.; Wang, Z.; Wu, J.; Wang, J.; Wang, S. In situ immobilization of silver nanoparticles for improving permeability, antifouling and anti-bacterial properties of ultrafiltration membrane. J. Membr. Sci. 2016, 499, 269-281. [CrossRef]

4. Zhang, Y.Q. Applications of natural silk protein sericin in biomaterials. Biotechnol. Adv. 2003, 20, 91-100. [CrossRef] 
5. Yang, M.; Wang, Y.; Cai, R.; Tao, G.; Chang, H.; Ding, C.; Zuo, H.; Shen, H.; Zhao, P.; He, H. Preparation and characterization of silk sericin/glycerol films coated with silver nanoparticles for antibacterial application. Sci. Adv. Mater. 2018, 10, 1-8. [CrossRef]

6. Aramwit, P.; Siritientong, T.; Kanokpanont, S.; Srichana, T. Formulation and characterization of silk sericin-pva scaffold crosslinked with genipin. Int. J. Biol. Macromol. 2010, 47, 668-675. [CrossRef] [PubMed]

7. Zhaorigetu, S.; Yanaka, N.; Sasaki, M.; Watanabe, H.; Kato, N. Inhibitory effects of silk protein, sericin on uvb-induced acute damage and tumor promotion by reducing oxidative stress in the skin of hairless mouse. J. Photochem. Photobiol. B Biol. 2003, 71, 11-17. [CrossRef]

8. Kundu, B.; Kundu, S.C. Silk sericin/polyacrylamide in situ forming hydrogels for dermal reconstruction. Biomaterials 2012, 33, 7456-7467. [CrossRef] [PubMed]

9. Chlapanidas, T.; Faragò, S.; Lucconi, G.; Perteghella, S.; Galuzzi, M.; Mantelli, M.; Avanzini, M.A.; Tosca, M.C.; Marazzi, M.; Vigo, D. Sericins exhibit ROS-scavenging, anti-tyrosinase, anti-elastase, and in vitro immunomodulatory activities. Int. J. Biol. Macromol. 2013, 58, 47-56. [CrossRef] [PubMed]

10. Chlapanidas, T.; Perteghella, S.; Leoni, F.; Faragò, S.; Marazzi, M.; Rossi, D.; Martino, E.; Gaggeri, R.; Collina, S. TNF- $\alpha$ blocker effect of naringenin-loaded sericin microparticles that are potentially useful in the treatment of psoriasis. Int. J. Mol. Sci. 2014, 15, 13624-13636. [CrossRef] [PubMed]

11. Faragò, S.; Lucconi, G.; Perteghella, S.; Vigani, B.; Tripodo, G.; Sorrenti, M.; Catenacci, L.; Boschi, A.; Faustini, M.; Vigo, D. A dry powder formulation from silk fibroin microspheres as a topical auto-gelling device. Pharm. Dev. Technol. 2016, 21, 453-462. [CrossRef] [PubMed]

12. Bari, E.; Arciola, C.R.; Vigani, B.; Crivelli, B.; Moro, P.; Marrubini, G.; Sorrenti, M.; Catenacci, L.; Bruni, G.; Chlapanidas, T. In vitro effectiveness of microspheres based on silk sericin and chlorella vulgaris or arthrospira platensis for wound healing applications. Materials 2017, 10, 983. [CrossRef] [PubMed]

13. Perteghella, S.; Martella, E.; De Girolamo, L.; Perucca Orfei, C.; Pierini, M.; Fumagalli, V.; Pintacuda, D.V.; Chlapanidas, T.; Viganò, M.; Faragò, S. Fabrication of innovative silk/alginate microcarriers for mesenchymal stem cell delivery and tissue regeneration. Int. J. Mol. Sci. 2017, 18, 1829. [CrossRef] [PubMed]

14. Crivelli, B.; Perteghella, S.; Bari, E.; Sorrenti, M.; Tripodo, G.; Chlapanidas, T.; Torre, M.L. Silk nanoparticles: From inert supports to bioactive natural carriers for drug delivery. Soft Matter 2018, 14, 546-557. [CrossRef] [PubMed]

15. Bari, E.; Perteghella, S.; Faragò, S.; Torre, M.L. Association of silk sericin and platelet lysate: Premises for the formulation of wound healing active medications. Int. J. Biol. Macromol. 2018, 119, 37-47. [CrossRef] [PubMed]

16. Bari, E.; Perteghella, S.; Marrubini, G.; Sorrenti, M.; Catenacci, L.; Tripodo, G.; Mastrogiacomo, M.; Mandracchia, D.; Trapani, A.; Faragò, S. In vitro efficacy of silk sericin microparticles and platelet lysate for intervertebral disk regeneration. Int. J. Biol. Macromol. 2018, 118, 792-799. [CrossRef] [PubMed]

17. Cai, R.; Tao, G.; He, H.; Song, K.; Zuo, H.; Jiang, W.; Wang, Y. One-step synthesis of silver nanoparticles on polydopamine-coated sericin/polyvinyl alcohol composite films for potential antimicrobial applications. Molecules 2017, 22, 721. [CrossRef] [PubMed]

18. Reddy, J.P.; Rhim, J.W. Characterization of bionanocomposite films prepared with agar and paper-mulberry pulp nanocellulose. Carbohydr. Polym. 2014, 110, 480-488. [CrossRef] [PubMed]

19. Wang, Y.; Cai, R.; Tao, G.; Wang, P.; Zuo, H.; Zhao, P.; Umar, A.; He, H. A novel AgNPs/sericin/agar film with enhanced mechanical property and antibacterial capability. Molecules 2018, 23, 1821. [CrossRef] [PubMed]

20. Liu, L.; Cai, R.; Wang, Y.; Tao, G.; Ai, L.; Wang, P.; Yang, M.; Zuo, H.; Zhao, P.; Shen, H. Preparation and characterization of AgNPs in situ synthesis on polyelectrolyte membrane coated sericin/agar film for antimicrobial applications. Materials 2018, 11, 1205. [CrossRef] [PubMed]

21. Aramwit, P.; Kanokpanont, S.; Nakpheng, T.; Srichana, T. The effect of sericin from various extraction methods on cell viability and collagen production. Int. J. Mol. Sci. 2010, 11, 2200-2211. [CrossRef] [PubMed]

22. He, H.; Rui, C.; Wang, Y.; Gang, T.; Guo, P.; Hua, Z.; Chen, L.; Liu, X.; Ping, Z.; Xia, Q. Preparation and characterization of silk sericin/pva blend film with silver nanoparticles for potential antimicrobial application. Int. J. Biol. Macromol. 2017, 104, 457. [CrossRef] [PubMed]

23. Seo, D.; Kim, J. Effect of the molecular size of analytes on polydiacetylene chromism. Adv. Funct. Mater. 2010, 20, 1397-1403. [CrossRef] 
24. Cui, J.; Wang, Y.; Postma, A.; Hao, J.; Hosta-Rigau, L.; Caruso, F. Monodisperse polymer capsules: Tailoring size, shell thickness, and hydrophobic cargo loading via emulsion templating. Adv. Funct. Mater. 2010, 20, 1625-1631. [CrossRef]

25. Zhu, L.P.; Yu, J.Z.; Xu, Y.Y.; Xi, Z.Y.; Zhu, B.K. Surface modification of pvdf porous membranes via poly(dopa) coating and heparin immobilization. Colloid Surface B 2009, 69, 152-155. [CrossRef] [PubMed]

26. Peng, F.; Wang, Q.; Shi, R.; Wang, Z.; You, X.; Liu, Y.; Wang, F.; Gao, J.; Mao, C. Fabrication of sesame sticks-like silver nanoparticles/polystyrene hybridnanotubes and their catalytic effects. Sci. Rep. 2016, 6, 39502. [CrossRef] [PubMed]

27. Xu, H.; Zhang, G.; Xu, K.; Wang, L.; Yu, L.; Xing, M.; Qiu, X. Mussel-inspired dual-functional peg hydrogel inducing mineralization and inhibiting infection in maxillary bone reconstruction. Mat. Sci. Eng. A-Struct. 2018, 90, 379-386. [CrossRef] [PubMed]

28. Ke, W.; Yun, Y.; Zhang, Y.; Deng, J.; Lin, C. Antimicrobial activity and cytocompatibility of silver nanoparticles coated catheters via a biomimetic surface functionalization strategy. Int. J. Nanomed. 2015, 10, 7241-7252.

29. Tacora Cauna, R.L.; Luna Mercado, G.I.; Bravo Portocarrero, R.; Mayta Hancco, J.; Choque Yucra, M.; Ibañez Quispe, V. Effect ofthe expansion pressure process by explosion and toast temperature on some functional and physicochemical characteristics on two varieties of cañihua (chenopodium pallidicaule aellen). Journal De Ciencia Y Tecnologia Agraria 2010, 10, 188-198.

30. Lu, Q.; Hu, X.; Wang, X.; Kluge, J.A.; Lu, S.; Cebe, P.; Kaplan, D.L. Water-insoluble silk films with silk i structure. Acta Biomater. 2010, 6, 1380-1387. [CrossRef] [PubMed]

31. Dreyer, D.R.; Miller, D.J.; Freeman, B.D.; Paul, D.R.; Bielawski, C.W. Elucidating the structure of poly(dopamine). Langmuir 2012, 28, 6428. [CrossRef] [PubMed]

32. Jin, Y.; Deng, D.; Cheng, Y.; Kong, L.; Xiao, F. Annealing-free and strongly adhesive silver nanowire networks with long-term reliability by introduction of a nonconductive and biocompatible polymer binder. Nanoscale 2014, 6, 4812-4818. [CrossRef] [PubMed]

33. Gómezordóñez, E.; Rupérez, P. Ftir-atr spectroscopy as a tool for polysaccharide identification in edible brown and red seaweeds. Food Hydrocolloid 2011, 25, 1514-1520. [CrossRef]

34. Tao, W.; Li, M.; Xie, R. Preparation and structure of porous silk sericin materials. Macromol. Mater. Eng. 2010, 290, 188-194. [CrossRef]

35. Jiang, Y.; Lu, Y.; Zhang, L.; Liu, L.; Dai, Y.; Wang, W. Preparation and characterization of silver nanoparticles immobilized on multi-walled carbon nanotubes by poly(dopamine) functionalization. J. Nanopart. Res. 2012, 14, 1-10. [CrossRef]

36. Roy, K.; Sarkar, C.K.; Ghosh, C.K. Rapid colorimetric detection of hg2+ ion by green silver nanoparticles synthesized using dahlia pinnata leaf extract. Green. Process. Synth. 2015, 4, 455-461. [CrossRef]

37. Kanmani, P.; Rhim, J.W. Antimicrobial and physical-mechanical properties of agar-based films incorporated with grapefruit seed extract. Carbohydr. Polym. 2014, 102, 708-716. [CrossRef] [PubMed]

38. Kumar, P.T.; Lakshmanan, V.K.; Anilkumar, T.V.; Ramya, C.; Reshmi, P.; Unnikrishnan, A.G.; Nair, S.V.; Jayakumar, R. Flexible and microporous chitosan hydrogel/nano zno composite bandages for wound dressing: In vitro and in vivo evaluation. ACS Appl Mater Interfaces 2012, 4, 2618-2629. [CrossRef] [PubMed]

39. Yang, M.; Wang, Y.; Gang, T.; Rui, C.; Peng, W.; Liu, L.; Ai, L.; Hua, Z.; Ping, Z.; Umar, A. Fabrication of sericin/agrose gel loaded lysozyme and its potential in wound dressing application. Nanomaterials 2018, 8, 235. [CrossRef] [PubMed]

40. Yao, Y.; Liu, H.; Ding, X.; Jing, X.; Gong, X.; Zhou, G.; Fan, Y. Preparation and characterization of silk fibroin/poly(l-lactide-co-caprolactone) nanofibrous membranes for tissue engineering applications. J. Bioact. Compat. Pol. 2015, 30, 14825-14829. [CrossRef]

41. Cai, R.; Tao, G.; He, H.; Guo, P.; Yang, M.; Ding, C.; Zuo, H.; Wang, L.; Zhao, P.; Wang, Y. In situ synthesis of silver nanoparticles on the polyelectrolyte-coated sericin/pva film for enhanced antibacterial application. Materials 2017, 10, 967. [CrossRef] [PubMed]

42. Wu, J.H.; Wang, Z.; Xu, S.Y. Preparation and characterization of sericin powder extracted from silk industry wastewater. Food Chem. 2007, 103, 1255-1262. [CrossRef]

43. He, H.; Tao, G.; Wang, Y.; Cai, R.; Guo, P.; Chen, L.; Zuo, H.; Zhao, P.; Xia, Q. In situ green synthesis and characterization of sericin-silver nanoparticle composite with effective antibacterial activity and good biocompatibility. Mat. Sci. Eng. C-Mater. 2017, 80, 509. [CrossRef] [PubMed] 
44. Karim, Z.; Mathew, A.P.; Grahn, M.; Mouzon, J.; Oksman, K. Nanoporous membranes with cellulose nanocrystals as functional entity in chitosan: Removal of dyes from water. Carbohydr. Polym. 2014, 112, 668-676. [CrossRef] [PubMed]

45. Tao, G.; Cai, R.; Wang, Y.; Song, K.; Guo, P.; Zhao, P.; Zuo, H.; He, H. Biosynthesis and characterization of AgNPs -silk/pva film for potential packaging application. Materials 2017, 10, 667. [CrossRef] [PubMed]

46. Janisha, J.; Rosamma, A. Deproteinised natural rubber latex grafted poly(dimethylaminoethyl methacrylate)-poly(vinyl alcohol) blend membranes: Synthesis, properties and application. Int. J. Biol. Macromol. 2017, 107, 1821.

47. Schillinger, U.; Lücke, F.K. Antibacterial activity of lactobacillus sake isolated from meat. Appl. Environ. Microb. 1989, 55, 1901.

48. Hwang, J.J.; Ma, T.W. Preparation, morphology, and antibacterial properties of polyacrylonitrile/montmorillonite/silver nanocomposites. Mater. Chem. Phys. 2012, 136, 613-623. [CrossRef]

(C) 2018 by the authors. Licensee MDPI, Basel, Switzerland. This article is an open access article distributed under the terms and conditions of the Creative Commons Attribution (CC BY) license (http://creativecommons.org/licenses/by/4.0/). 